\title{
Green synthesis process of a polyurethane-silver nanocomposite having biocide surfaces
}

\author{
Issam Mtimet ${ }^{1}$, Laurence Lecamp ${ }^{1}$, Nasreddine Kebir ${ }^{1}$, Fabrice Burel ${ }^{1}$ and Thierry Jouenne ${ }^{2}$ \\ Silver nanoparticles were prepared by microwave irradiation of a silver nitrate $\left(\mathrm{AgNO}_{3}\right)$ aqueous solution in poly(ethylene glycol) \\ (PEG) in the absence of other chemicals. Optimal monodispersed, stable and spherical silver nanoparticles with $35 \pm 5 \mathrm{~nm}$ \\ diameter were obtained after $20 \mathrm{~min}$ of microwave irradiation at $120{ }^{\circ} \mathrm{C}$ in the presence of PEG 2000. Polyurethanes (PUs) \\ containing silver $(\mathrm{Ag})$ nanoparticles $\left(35 \mathrm{~nm}, 1 \times 10^{-3}-3 \times 10^{-3} \mathrm{wt}-\%\right)$ were then prepared by introducing the nanoparticles \\ suspension at different times of the waterborne PU synthesis. The Ag nanoparticles were found to be well dispersed in PU \\ when introduced initially with the reagents. In these conditions, the PEG was well chemically linked to the PU chains and \\ the presence of Ag nanoparticles didn't impact the thermo-mechanical properties of the PU. The prepared silver nanoparticles \\ exhibited biocidal properties against Pseudomonas aeruginosa and Enterococcus faecalis both in liquid suspension and on \\ the PUs surfaces.
}

Polymer Journal (2012) 44, 1230-1237; doi:10.1038/pj.2012.90; published online 23 May 2012

Keywords: antibacterial activity; poly(ethylene glycol); silver nanoparticles; waterborne PU

\section{INTRODUCTION}

Polyurethanes (PUs) are commonly used as biomaterials owing to their good biocompatibility and mechanical properties. ${ }^{1,2}$ More particularly, the development of waterborne PU formulations has dramatically increased because of the environmental demand. ${ }^{3}$ However, they are also good candidates for the microbial colonization and biofilm formation onto their surfaces, which are usually difficult to eradicate. Actually, the most used preventive strategy consists in limiting the adhesion of microorganisms on the surfaces. A first solution consists in the grafting of specific functional groups onto the polymer backbone. It has thus been demonstrated that most of the linear ethoxylated non-ionic surfactants as well as quaternary ammonium are able to prevent the adhesion of bacteria thanks to their anti-adhesive effect on hydrophobic surfaces. ${ }^{45}$ The second solution is to incorporate bacterial agents onto the polymer matrix. Metal particles, mainly silver and copper, or mineral fillers functionalized by antibacterial polymers are then relevant. ${ }^{6-8}$

The antibacterial activity of silver ions has been well known since ancient times. ${ }^{9,10}$ It has been particularly demonstrated that, in low concentrations, silver is non-toxic to human cells. ${ }^{11,12}$. The knowledge of biocidal effect of silver nanoparticles is more recent and, although the bactericidal mechanism of silver nanoparticles is not well known, some researchers supported the idea that silver species release $\mathrm{Ag}^{+}$ ions, which interact with the thiol groups in bacteria proteins, affecting the DNA replication. ${ }^{13}$ It has been also reported that $\mathrm{Ag}^{+}$ ions uncouple the respiratory chain from oxidative phosphorylation or collapse the proton-motive force across the cytoplasmic membrane. ${ }^{10}$ However, it is noteworthy that silver nanoparticles interactions with bacteria are dependent on the nanoparticle size and shape. ${ }^{9,14,15}$ Thus, the antibacterial activity decreases when the silver particle size increases owing to decrease of the surface exchange. ${ }^{9,13}$

The most extensive method for the incorporation of silver nanoparticles into polymer consists in preparing the metal particles ex situ. To limit the problems of aggregation and/or of bad dispersion, the nanoparticles surface is often modified by covalent bonds or coated with an appropriate polymer to increase compatibility between Ag nanoparticles and the polymer matrix. However, these solutions are not always successful. ${ }^{16,17}$ In this work, we propose an alternative to this compatibility problem by incorporating, in chemical structure of the polymer matrix, the polymer that is used to the silver nanoparticles coating. Silver nanoparticles were synthesized according to a solventless reducing process carried out under microwaves and using poly(ethylene glycol) (PEG) as reducing and stabilizing agent. The obtained nanoparticles were in a solid state suspension, allowing their easy and safe use. Their antibacterial activity was determined by the minimum inhibitory concentration (MIC) assessment against Gram-negative and Gram-positive bacteria. Then, the prepared silver suspension was introduced during the synthesis of waterborne polyurethane (PUD). Thanks to its hydroxyl end-groups, PEG was expected to be chemically incorporated into the PU backbone. Finally, PU-Ag nanocomposites were obtained by water evaporation and then characterized in terms of physicochemical and antibacterial properties. 


\section{EXPERIMENTAL PROCEDURE}

\section{Silver nanoparticles suspension}

Synthesis of Ag nanoparticles was performed using a CEM Discover Microwave System (Orsay, France). In a typical procedure, $2 \mathrm{~g}$ of PEG $\left(M_{\mathrm{W}}=2000\right.$ $\mathrm{g} \mathrm{mol}^{-1}$, Aldrich, Lyon, France) and $0.1 \mathrm{ml}$ of a $0.015 \mathrm{moll}^{-1}$ silver nitrate $\left(\mathrm{AgNO}_{3}\right.$, Aldrich) aqueous solution were placed in a closed tube out of quartz, under magnetic stirring. The tube was then placed in a microwave oven that was operated at $120^{\circ} \mathrm{C}$ and a frequency of $2450 \mathrm{MHz}$ for $20 \mathrm{~min}$. The colorless mixture instantaneously turned to the characteristic pale yellow color, indicating the formation of silver nanoparticles.

The concentration of the remaining silver ions, and consequently, the reaction yield, were determined from a potential measurement using a calibration curve established thanks to standard $\mathrm{Ag}^{+}$aqueous solutions containing PEG and a combined silver electrode.

\section{Waterborne polyurethane (PUD) synthesis}

Polyurethane is based on polytetramethyleneglycol (PTMG, $M_{\mathrm{w}}=650 \mathrm{~g} \mathrm{~mol}^{-1}$, Soprema, Strasbourg, France), dimethylolpropionate triethylammonium salt (DMPTA, Aldrich) as ionic chain extender and a slight excess of 4,4'methylenedicyclohexyldiisocyanate $\left(\mathrm{H}_{12} \mathrm{MDI}\right.$, Aldrich). In a typical procedure, $13.7 \times 10^{-3} \mathrm{~mol}(8.94 \mathrm{~g})$ of PTMG was charged into a $250-\mathrm{ml}$ round bottom flask equipped with a mechanical stirrer (450 r.p.m.), a switchable inlet for nitrogen and a vacuum connector. PTMG was first degassed for $1 \mathrm{~h}$ by a graduated vacuum up to $10^{-2} \mathrm{~mm} \mathrm{Hg}$ at $60^{\circ} \mathrm{C}$. Moreover, $2.2 \times 10^{-3} \mathrm{~mol}$ $(0.29 \mathrm{~g})$ of DMPA, $2.2 \times 10^{-3} \mathrm{~mol}(0.22 \mathrm{~g})$ of triethylamine (Acros Organics, Illkirch, France) and $14.56 \mathrm{~g}$ of MEK (Acros) were introduced in an Erlenmeyer and stirred at room temperature for $15 \mathrm{~min}$ before addition in the previous round bottom flask. The stirring was still carried out for $15 \mathrm{~min}$ at $60^{\circ} \mathrm{C}$ under nitrogen flux. A total of $20 \times 10^{-3} \mathrm{~mol}$ of $\mathrm{H}_{12} \mathrm{MDI}$ (5.34 g) was then introduced carefully as rapidly as possible and the mixture was stirred for $15 \mathrm{~min}$. Lastly, $20 \mu \mathrm{l}$ of catalyst (DBTL, Aldrich) was added. The reaction was allowed to proceed under stirring for $6 \mathrm{~h}$ and the reaction mixture was cooled at room temperature. Deionized water was introduced into the reaction mixture with vigorous stirring until to obtain an aqueous dispersion with $20 \%$ dried extract. After MEK evaporation under vacuum, ethylenediamine (Aldrich) was slowly put into reaction mixture for further chain extension. The reaction was carried out under stirring until complete disappearance of isocyanate functions.

\section{Preparation of PU-Ag composites}

PU-Ag nanocomposite films were prepared by adding a calculated weight of $\mathrm{Ag}$ nanoparticle suspension to the PUD. The synthesis procedure was then the same as previously described.

Films for bulk and surface properties studies were obtained by casting the aqueous PU dispersions into PTFE molds. After water evaporation, the films were dried at $50{ }^{\circ} \mathrm{C}$ for at least $48 \mathrm{~h}$ to remove any residual solvent.

\section{Characterization of the nanoparticle suspension}

Characteristic optical properties of Ag nanoparticles were determined using Perkin Elmer Lambda 16 UV-Vis spectrophotometer (Perkin Elmer, Waltham, MA, USA). Spectra were recorded using $1 \mathrm{~cm}^{3}$ quartz cell and the dispersion of silver particles was diluted four times in acetonitrile. Size, shape and particle size distributions were determined using dynamic light scattering analysis on a Malvern Zetasizer Nano ZS (Malvern, Worcestershire, UK). The suspension of silver particles was diluted ten times in water.

\section{Physicochemical properties of the PU-Ag nanocomposites}

Surface analyses were performed by the 'Centre Technologique des Microstructures de l'Université de Lyon (France)'. Scanning electron microscope images were recorded with a Hitachi S800 FEG microscope (Hitachi, Tokyo, Japan) operating with an accelerating voltage of $15 \mathrm{kV}$. Scanning electron microscope was equipped with an energy-dispersive X-ray spectroscopy system microanalysis. Data were acquired using IDFix and MaxView of SamX software (Saint Laurent du Var, France). Carbon, oxygen and silver were particularly detected.

Thermogravimetric analysis was carried out with a thermogravimetric analyzer (TA Instruments, New Castle, DE, USA, TGA Q500). Samples were submitted to a heating rate of $10^{\circ} \mathrm{C} \mathrm{min}^{-1}$ under nitrogen.
Differential scanning calorimetry (DSC) measurements were performed on the PU samples using a DSC Q2000 (TA Instruments). Samples were submitted to a heating rate of $10{ }^{\circ} \mathrm{C} \mathrm{min}{ }^{-1}$ under nitrogen.

Tensile tests (Young's modulus $E$ and failure strain $\varepsilon$ ) were performed on the PU samples using an Instron 5543 testing machine (Norwood, MA, USA). All tests were carried out until rupture with a $2-\mathrm{mm} \mathrm{min}^{-1}$ cross-head speed and a load cell of $500 \mathrm{~N}$. The size of each dumbbell-shaped specimen (around $30 \times 10 \times 0.7 \mathrm{~mm}$ ) was precisely determined. The tensile modulus $(E)$ was determined as the tangent at origin of the curve stress-strain. The values obtained for the mechanical parameters were averaged.

Polymer samples $\left(10 \times 10 \times 0.7 \mathrm{~mm}^{3}\right)$ were swollen in water for $24 \mathrm{~h}$. Afterwards, samples were first weighed $\left(m_{\mathrm{s}}\right)$, then dried for $24 \mathrm{~h}$ at $40^{\circ} \mathrm{C}$, until constant mass, and weighed again $\left(m_{\mathrm{d}}\right)$. Swelling $(Q)$ is calculated as:

$$
Q=\frac{m_{\mathrm{s}}-m_{\mathrm{d}}}{m_{\mathrm{d}}} \times 100
$$

Surface tensions of the PU films were evaluated by static contact angle $(\theta)$ measurements on the air-facing surfaces of the samples with three liquids: water, dimethylformamide and glycerol using a Digidrop ASE goniometer (GBX, Bourg de Péage, France). Nine measurements on different points were performed to calculate the mean static contact angle and its standard deviation. According to the Owens-Wendt relationship (1) the dispersive $\gamma_{s}^{\mathrm{d}}$ and polar $\gamma_{\mathrm{s}}^{\mathrm{p}}$ components of the PU films were determined.

$$
\frac{\left(1+\cos \theta_{i}\right) \gamma_{i}}{2 \sqrt{\gamma_{i}^{\mathrm{d}}}}=\sqrt{\gamma_{\mathrm{s}}^{\mathrm{p}}} \times \sqrt{\frac{\gamma_{i}^{\mathrm{p}}}{\gamma_{i}^{\mathrm{d}}}}+\sqrt{\gamma_{\mathrm{s}}^{\mathrm{d}}}
$$

where $\gamma_{i}, \gamma_{i}^{\mathrm{d}}, \gamma_{i}^{\mathrm{p}}$ are the solvent superficial tension parameters.

Furthermore, the polarity of each side can be computed according to:

$$
P=\frac{\gamma_{s}^{\mathrm{p}}}{\gamma_{\mathrm{s}}}
$$

where $\gamma_{s}$ is the material superficial tension $\left(\gamma_{\mathrm{s}}=\gamma_{\mathrm{s}}^{\mathrm{p}}+\gamma_{\mathrm{s}}^{\mathrm{d}}\right)$.

\section{Bacterial strains and growth conditions}

Bacterial strains and growth conditions. Pseudomonas aeruginosa (PA01) and Enterococcus faecalis (EF29212) were used. Bacteria were maintained in glycerol stocks and stored at $-24^{\circ} \mathrm{C}$. Cultures were performed by inoculating an aliquot of the bacterial suspension in $40 \mathrm{ml}$ of Mueller Hinton Broth medium. Flasks were incubated for $24 \mathrm{~h}$ at $37^{\circ} \mathrm{C}$ in a gyratory water bath shaker (agitation speed, $115 \mathrm{rev} \mathrm{min}{ }^{-1}$ ). Bacteria were harvested by centrifugation ( 3500 r.p.m. for $15 \mathrm{~min}$ ) and suspended again in $10 \mathrm{ml}$ of sterile distilled water.

Antimicrobial activity of silver nanoparticles. MIC values of the synthesized nanoparticle suspension were determined against $P$. aeruginosa and E. faecalis by two methods:

1. Bacterial numeration was performed by plating out $25 \mu \mathrm{l}$ of bacteria suspension inoculated with silver suspension at variable concentration on Plate Count Agar. After incubation for $24 \mathrm{~h}$ at $37^{\circ} \mathrm{C}$, the number of bacteria was expressed as colony forming units (CFU) $\mathrm{ml}^{-1}$ of dispersion.

2. Disposable microtitration plates were used for the tests. The nanoparticles in dispersion form were serially diluted 2-13 times with $500 \mu$ of Mueller Hinton Broth inoculated with bacteria at a concentration of $10^{6} \mathrm{CFU} \mathrm{ml}^{-1}$. The concentration $(N)$ of cell population $(\mathrm{CFU})$ within bacteria suspensions for each Ag nanoparticles concentration was estimated by optical density measurement at $550 \mathrm{~nm}$ (no absorption of Ag nanoparticles) using a Varian Cary 100 spectrophotometer (Varian, Middleburg, The Netherlands), referred to a calibration curve: $N\left(\mathrm{CFU} \mathrm{ml}{ }^{-1}\right)=1 \times 10^{9} \times \mathrm{OD}_{550}$.

\section{Antimicrobial activity of PU-Ag nanocomposites}

Kinetics of bacteria adhesion and viability on PU-Ag nanocomposites surfaces. Prior to use, five coupons (squares of $7 \mathrm{~mm}$ side and $0.7 \mathrm{~mm}$ thick) of each material were sterilized for 30 min under UV radiation. Each coupon was then placed in a flask containing $25 \mathrm{ml}$ of distilled sterilized water. Flasks were inoculated with a 24-h-old culture of bacteria to get a suspension concentration of $10^{7} \mathrm{CFU} \mathrm{ml}{ }^{-1}$ and then incubated at $37^{\circ} \mathrm{C}$ in a gyratory bath (agitation 
speed, $\left.115 \mathrm{rev} \mathrm{min}^{-1}\right)$. Coupons were picked up after several contact times (that is, after $30 \mathrm{~min}, 1,2,3,5$ and $7 \mathrm{~h}$ ), and rinsed with sterile distilled water. Adherent cells were recovered by sonication $(3 \mathrm{~min}$ ) of the material in $3 \mathrm{ml}$ of sterile distilled water (Deltasonic bath, Meaux, France). The resulting cell suspension was mixed by vortexing for $1 \mathrm{~min}$. Bacterial enumeration was performed by plating out $50 \mu \mathrm{l}$ of $1 / 10$ and $1 / 100$ dilutions of the suspension on Plate Count Agar. After incubation for $24 \mathrm{~h}$ at $37^{\circ} \mathrm{C}$, the number of bacteria

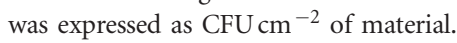

Assessment of bactericidal efficiency (Live and Dead test) on PU-Ag nanocomposites surfaces. A 40- $\mu \mathrm{l}$ sessile droplet of $P$. aeruginosa or E. faecalis suspensions in distilled water $\left(3.7 \times 10^{8} \mathrm{CFU} \mathrm{ml}^{-1}\right)$ was deposed and spread on the studied surfaces $\left(1 \mathrm{~cm}^{2}\right)$. The bacteria were allowed to sediment on the substrate for $10 \mathrm{~min}$. After that, the bacteria remaining in the solution were washed away by flushing the substrate with distilled water and then a $40-\mu l$ droplet of water was deposed and spread on the surfaces for $35 \mathrm{~min}$. After, water is removed from surfaces and a 40- $\mu$ l droplet of mixture of aqueous solutions of two fluorescent markers: the SYTO 9 (L7012, molecular probes, $2 \times 10^{-5} \mathrm{mmoll}^{-1}$ ) and the propidium iodide (L7012, Invitrogen, Cergy-Pontoise, France, $1.2 \times 10^{-4}$ mmoll $1^{-1}$ ), were then deposed and spread on these surfaces for $15 \mathrm{~min}$. Then, the surface imaging was carried out with a Leica Microsystems (RueilMalmaison, France) SP2 upright confocal laser scanning microscope (DM RXA2) equipped with an Acousto-Optical Beam Splitter system and using a $63 \times$ water immersion objective with numerical aperture 1.32 (Leica Microsystems). SYTO 9 was excited at $476 \mathrm{~nm}$ and observed from 485 to $540 \mathrm{~nm}$, and propidium iodide was excited at $514 \mathrm{~nm}$ and observed from 580 to $670 \mathrm{~nm}$. The adsorbed bacteria appear as green dots if still viable and as red dots if their membrane has been damaged following contact with silver species.

\section{RESULTS AND DISCUSSION}

\section{Synthesis and characterization of the silver nanoparticle} suspensions

The chemical reduction of silver salt in the presence of any stabilizing agent is the most used method for the preparation of silver colloid. Most commonly, the stabilizing agents used are polymers ${ }^{18}$ and surfactants. ${ }^{19}$ Ethylene glycol and diols were particularly used as reducing agent to prepare metal particles through the so-called polyol process at high temperatures. ${ }^{20}$ Indeed, ethylene glycol is an environmentally benign material and its polymer, PEG, has been widely applied in pharmaceutical and biomedical industries as prodrugs. C. Luo et al. ${ }^{14}$ have prepared silver nanoparticles having an average diameter of $80 \mathrm{~nm}$ with a large size distribution after $1 \mathrm{~h}$ of conventional heating at $120^{\circ} \mathrm{C}$ by exploiting PEG (PEG 2000). However, the control of the reducing reaction is difficult and large metal particles are often formed.

In this work, PEG was also used both as reducing and stabilizing agent to produce silver nanoparticles but conventional heating was replaced by microwave heating. Indeed, microwave provides rapid and homogeneous heating of the reaction mixture, so that uniform nucleation and growth conditions as well as a shorter crystallization time are obtained, leading to uniform nanomaterials with small sizes. $^{21,22}$

The influence of several parameters on the synthesis of $\mathrm{Ag}$ nanoparticles was investigated to determine the optimized conditions. Temperature was the first investigated parameter. The PEG 2000 was used and the formation of silver nanoparticles from $\mathrm{Ag}^{+}$ions at a concentration of $15 \times 10^{-3} \mathrm{moll}^{-1}$ was followed by recording the evolution of the absorbance solution by UV-visible spectroscopy. Silver nanoparticles were first prepared at low temperature, but the reduction reaction was not completed within $1 \mathrm{~h}$ as evidenced by the low absorption peak of the particles suspension. At $80^{\circ} \mathrm{C}$, the appearance of an absorption maximum at around $400 \mathrm{~nm}$ was observed after $40 \mathrm{~min}$ of heating, indicating the formation of spherical silver nanoparticles. ${ }^{14,23,24}$ By increasing gradually the reaction temperature, the intensity and the width of this plasmon peak were enhanced with a shift of wavelength towards higher values, meaning that larger silver nanoparticles were formed. ${ }^{14}$ Figure 1 shows the influence of temperature on the reaction time to reach the maximum of absorbance at $400 \mathrm{~nm}$ (that is, reduction time). Actually, the reduction time was decreased when the temperature was raised. The optimal temperature leading to adequate particle size and reduction time, and allowing comparison with literature data ${ }^{14}$ was $120^{\circ} \mathrm{C}$.

Figure 2 shows the effect of reaction time under microwave heating on the maximum absorbance at $400 \mathrm{~nm}$ and the particle size as well as the reaction yield at $120^{\circ} \mathrm{C}$. For $20 \mathrm{~min}$ of heating time, the reaction seems complete with a $80 \%$ reaction yield. Between 20 and $60 \mathrm{~min}$, the yield remained constant but the particle size increased slightly. After $1 \mathrm{~h}$ of reaction time, the reduction yield $\eta$ increased up to $100 \%$ but the formed silver nanoparticle size also increased.

Figure 3 shows the change in the solution absorbance at around $400 \mathrm{~nm}$ and particle size as a function of the precursor concentration for $20 \mathrm{~min}$ of heating time at $120^{\circ} \mathrm{C}$. In a logical way, the higher the concentration of $\mathrm{Ag}^{+}$ions, the higher is the absorbance (and the concentration) of silver nanoparticles. Absorbance and particles size do not vary significantly for $\mathrm{AgNO}_{3}$ concentration above 0.02 moll ${ }^{-1}$.

Figure 4 shows the experimental UV-Visible spectra of the silver nanoparticles using different molecular weight PEG as reducing agent at $120^{\circ} \mathrm{C}$ for $20 \mathrm{~min}$ under microwave. A weak plasmon peak using PEG 400 emerged at $405 \mathrm{~nm}$, showing that silver nanoparticles were developed at a relatively low concentration (yield of silver formation $\eta=15 \%)$. The intensity of this plasmon peak was significantly increased when PEG 1500 was used and the size of silver nanoparticles was around $35 \mathrm{~nm}(\eta=75 \%)$. In the case of PEG 2000, a slight enhancement related to the peak of $405 \mathrm{~nm}$ was still observed without relevant change of the particle size $(\eta=80 \%)$. With the further increase of PEG molecular weight to 6000 , the absorption band of silver nanoparticles shifted to $400 \mathrm{~nm}$, and the intensity was significantly enhanced without a significant increase of the reaction yield $(\eta=83 \%)$. Additionally, the peak around $400 \mathrm{~nm}$ broadened. Moreover, a new shoulder appeared around $300 \mathrm{~nm}$, which could be assigned to the development of larger dimension nanoprism. ${ }^{14}$ The $\mathrm{PEG} / \mathrm{AgNO}_{3}$ molar ratio certainly has an important role in the

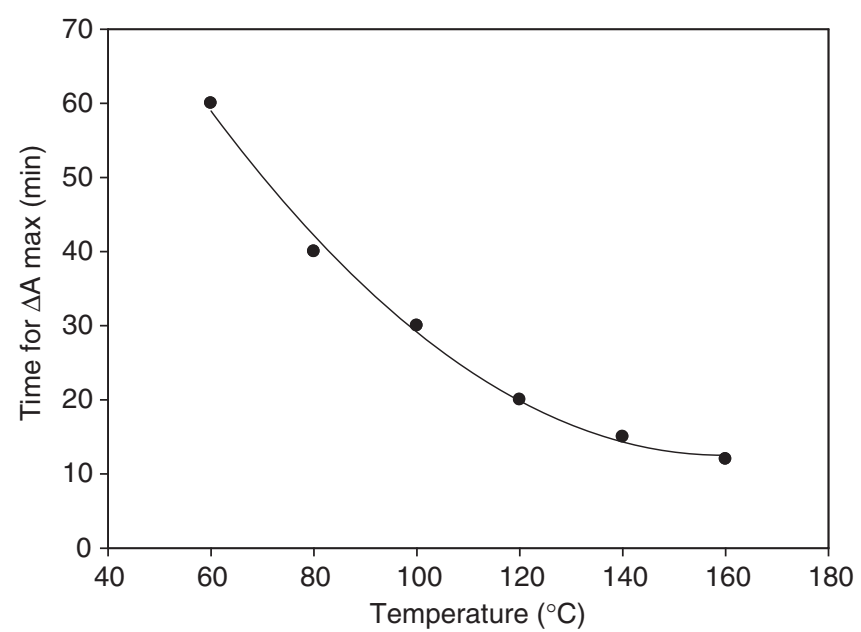

Figure 1 Influence of temperature on the reaction time needed to reach the maximum of absorbance at $400 \mathrm{~nm}$ for $\left[\mathrm{AgNO}_{3}\right]=15 \times 10^{-3} \mathrm{moll}^{-1}$ and PEG 2000. 


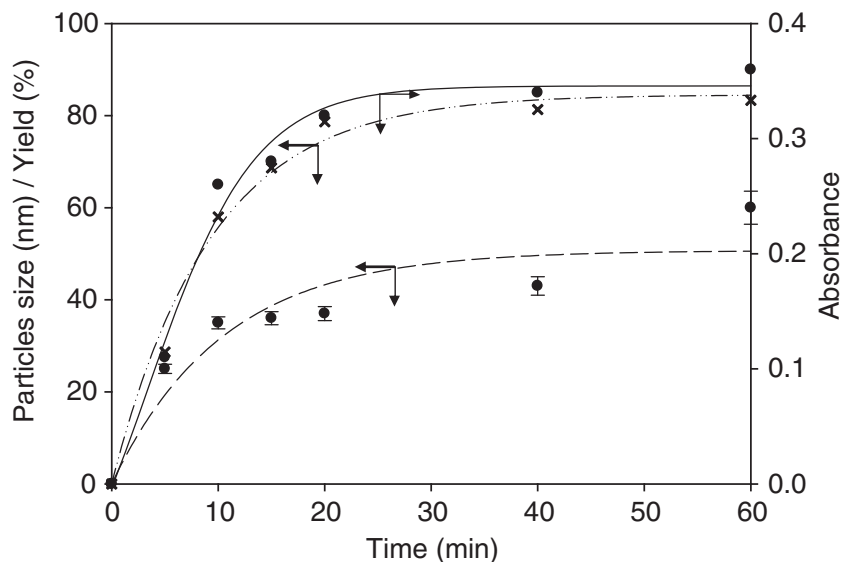

Figure 2 Influence of the reaction time under microwave at $T=120^{\circ} \mathrm{C}$ for $\left[\mathrm{AgNO}_{3}\right]=15 \times 10^{-3} \mathrm{moll}^{-1}$ on: $(x)$ the reaction yield, $(\bullet)$ the maximum absorbance at $\lambda=400 \mathrm{~nm}$ and $(\bullet)$ the average particle size.

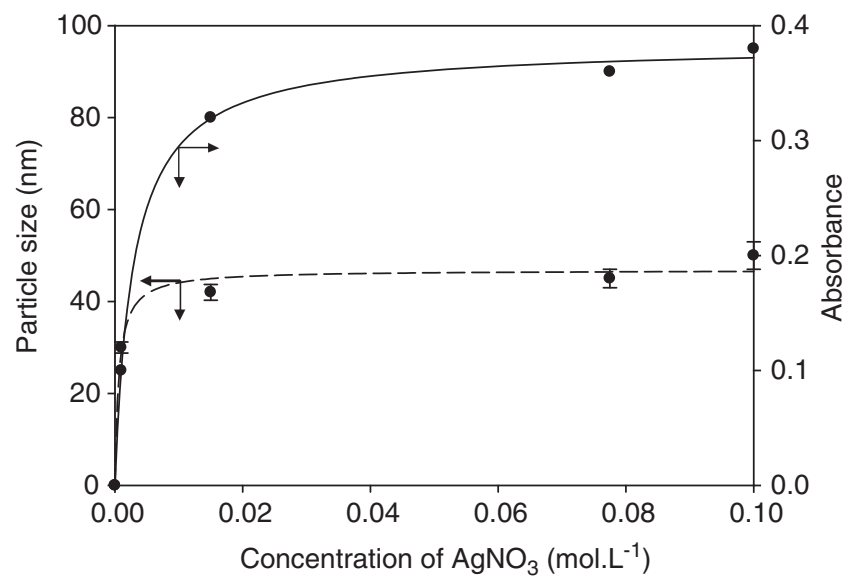

Figure 3 Maximum absorbance and average size of particles as a function of $\mathrm{AgNO}_{3}$ concentration after $20 \mathrm{~min}$ under microwave at $T=120^{\circ} \mathrm{C}$.

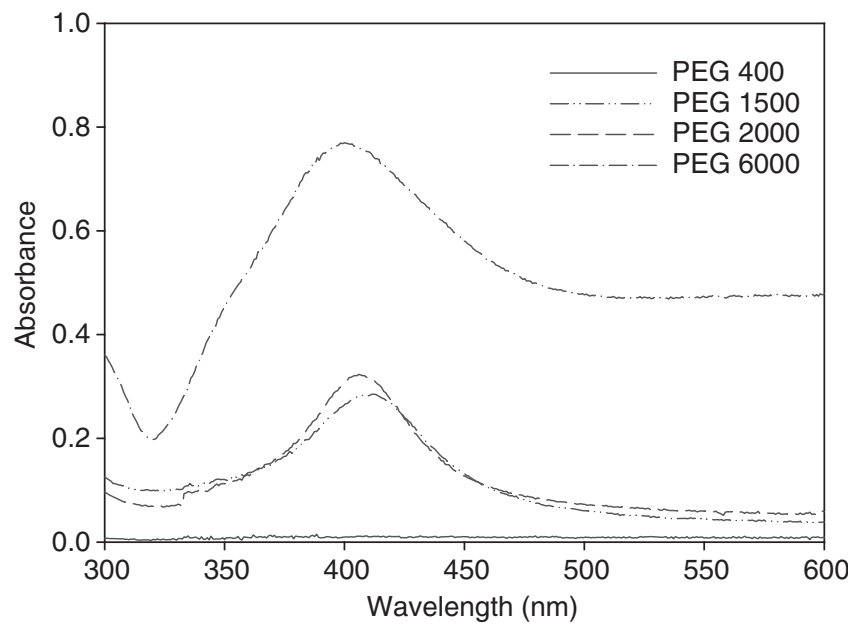

Figure 4 UV-Visible absorption spectra of silver nanoparticles prepared at $120^{\circ} \mathrm{C}$ for $20 \mathrm{~min}$ using different polymer chain lengths of PEG.

morphology of final particles. Indeed, a heavy coverage of PEG on the surfaces of the nanoparticles results in an isotropic growth leading to small nanostructures, as mentioned by Tsuji et al. ${ }^{21}$ in the case of the

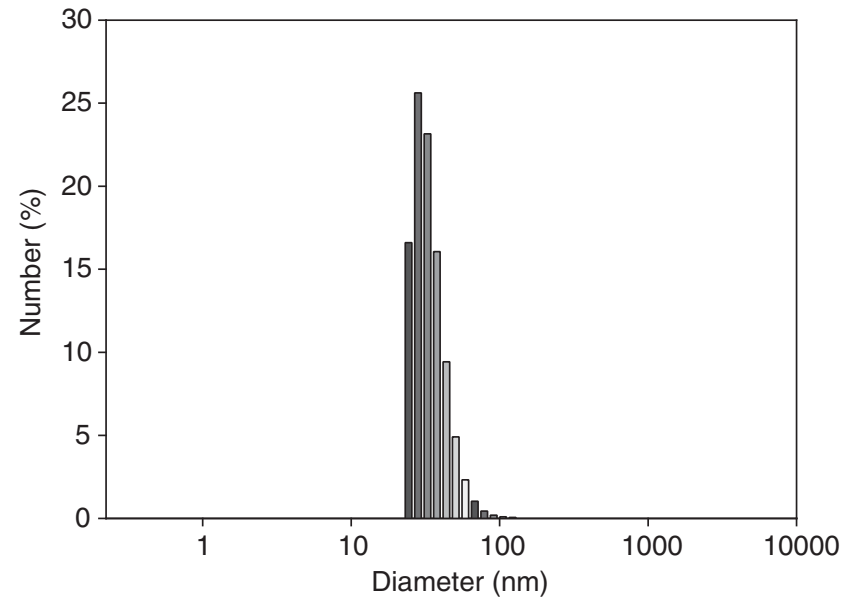

Figure 5 Particle size distribution for $t=20 \mathrm{~min},\left[\mathrm{AgNO}_{3}\right]=0.015 \mathrm{~mol} \mathrm{I}^{-1}$, PEG 2000 and $T=120^{\circ} \mathrm{C}$.

use of polyvinylpyrrolidone with different chain lengths for the preparation of gold nanostructures. In our experiments, the PEG weight was fixed to $2 \mathrm{~g}$, so that the increase in the PEG chain length leads to a decrease in the PEG/AgNO 3 molar ratio, and hence, to a decrease in the coverage particles. For PEG 6000, this decrease is too marked and favours the appearance of nanostructures with various size and geometry. On the other hand, in spite of the increase in the amount of hydroxyl groups when the PEG molar weight decreases, the reduction kinetics decreased, as also observed by Luo et al. ${ }^{14}$ under conventional heating. These authors have attributed this phenomenon to a more significant stabilization of $\mathrm{Ag}^{+}$ions by short PEG chains, which effectively inhibits the reduction yield.

Finally, the optimum synthesis conditions of silver nanoparticles were: $20 \mathrm{~min}$ under microwave at $\mathrm{T}=120^{\circ} \mathrm{C},\left[\mathrm{AgNO}_{3}\right]=0.015$ moll ${ }^{-1}$, use of PEG 2000. Compared with conventional heating, ${ }^{14}$ the microwave irradiation allowed reducing the reaction time from 60 to $20 \mathrm{~min}$, but also the average size of silver nanoparticles from 80 to $35 \mathrm{~nm}$ with a size distribution of $50 \mathrm{~nm}$ width, as shown in Figure 5.

\section{Antibacterial properties of the silver nanoparticle suspensions}

The antibacterial activity of the Ag nanoparticle suspensions was characterized against $P$. aeruginosa (Gram-negative) and E. faecalis (Gram-positive). These two bacteria were chosen because they are among the most resistant bacteria. Once checked the absence of antibacterial activity from PEG molecules, the MIC of synthesized nanoparticles was determined according to two methods, that is, bacterial numeration onto Agar plate or by optical density (OD) measurements.

The first method gave MIC values estimated in the range $30-40 \mu \mathrm{g} \mathrm{ml}^{-1}$ for both $P$. aeruginosa and E. faecalis. The second method was consistent with the first one in terms of MIC values. Indeed, the bacterial growth was dramatically inhibited for a $35 \mu \mathrm{g} \mathrm{ml}^{-1}$ nanoparticle concentration against the two species. This value is close to those already reported for silver particles (between $6.75 \mu \mathrm{g} \mathrm{ml}^{-1}$ for $10 \mathrm{~nm}$ diameter particles with ethylene glycol as stabilizing agent, and $54 \mu \mathrm{g} \mathrm{ml}^{-1}$ for $25 \mathrm{~nm}$ diameter particles with galactose as stabilizing agent for P. aeruginosa, Staphylococcus aureus and Staphylococcus epidermidis). ${ }^{9,25}$ In addition, the present results suggest that silver nanoparticles, which were prepared using PEG as reducing agent, exhibit a lower antibacterial action compared with those synthesized by using ethylene glycol, but a higher efficiency 
compared with galactose-stabilized silver nanoparticles in spite of a little bit higher particle size.

\section{Elaboration of the PU-Ag nanocomposites}

PU was prepared in a two-step method as described elsewhere. ${ }^{26,27}$ Briefly, a prepolymer based on PTMG, dimethylolpropionate triethylammonium salt as ionic chain extender (2 wt-\%) and a slight excess of $\mathrm{H}_{12} \mathrm{MDI}([\mathrm{NCO}] /[\mathrm{OH}]=1.3$ ) was first synthesized (Scheme 1). The isocyanate-terminated ionic PU was then dispersed by adding water and evaporating MEK and extended by reaction with ethylenediamine to lead to a PU-urea. After water evaporation and drying, PU films were obtained.

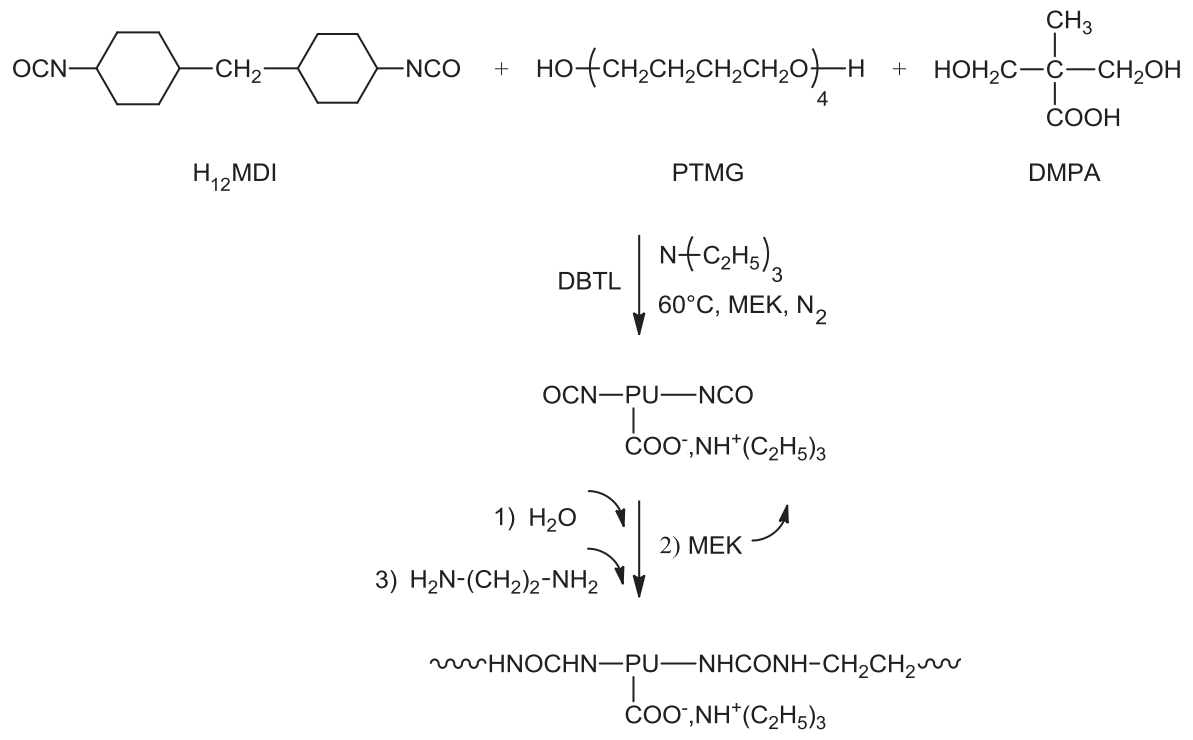

Scheme 1 Synthesis scheme of waterborne PU.
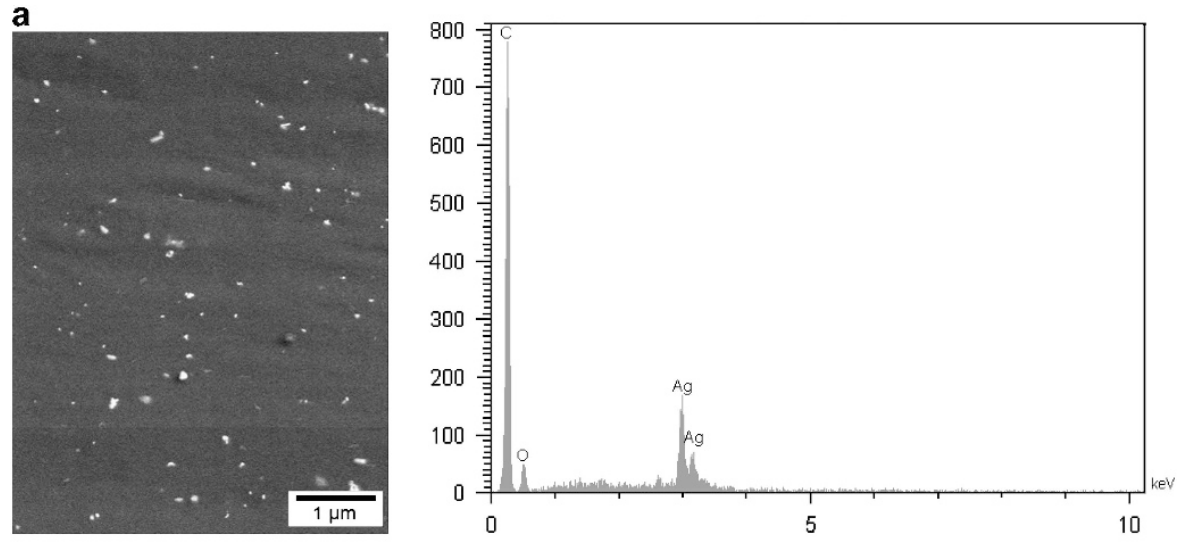

b
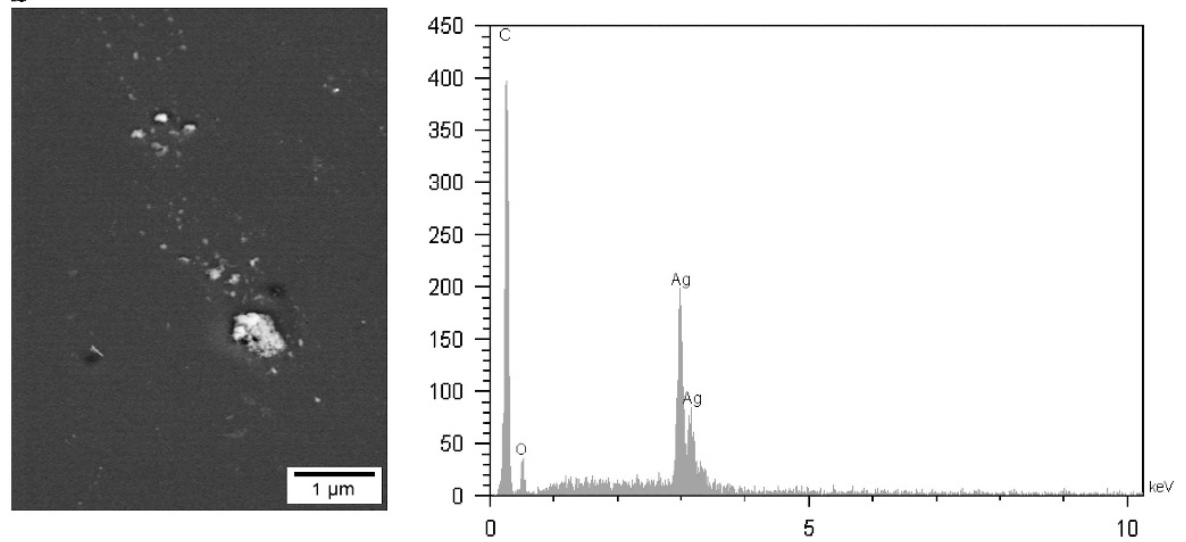

Figure 6 Scanning electron microscope images and energy-dispersive X-ray spectroscopy analyses of (a) PU1 and (b) PU2 nanocomposites filled with 35 p.p.m. of Ag nanoparticles. A full color version of this figure is available at The Journal of Antibiotics journal online. 
Two incorporation ways were tested to prepare the PU-Ag nanocomposites. The silver nanoparticle suspension was added either at the beginning of the PUD synthesis process leading to a final dried material called PU1 or, after water dispersion of the prepolymer leading to a final dried material called PU2. The amounts of Ag particles were introduced in the range 15-60 p.p.m. in the final dried materials. A PU material including PEG in the same proportions than those in the previous composite materials was also prepared as control.

The surface morphologies of PU-Ag nanocomposites incorporated with 35 p.p.m. of Ag by scanning electron microscope and energydispersive X-ray spectroscopy are presented in Figure 6. The energydispersive X-ray spectroscopy results confirmed the presence of $\mathrm{Ag}$ nanoparticles on the PU surface. The micrographs show a well homogeneous distribution of these particles (light gray spots) with a diameter around $50 \mathrm{~nm}$ when silver nanoparticles were introduced at the beginning of the PUD synthesis (PU1-Figure 6a). On the other hand, PU2 (Figure 6b) exhibits deformed aggregates due to a bad incorporation of the Ag-PEG suspension into the waterborne PU. This was confirmed by the DSC thermogram of PU2 that presents a melting peak of PEG at $50^{\circ} \mathrm{C}$. In contrast, in the case of PU1, PEG was perfectly incorporated in the PU chains, as evidenced by the absence of the endothermic PEG melting peak.

\section{Antibacterial properties of the PU-Ag nanocomposites}

Typically, the examination of the bactericidal activity of a polymer is performed by placing bacteria in contact with a film prepared from the material. The bactericidal activity of the polymer was examined against the two previously mentioned bacteria $P$. aeruginosa and E. faecalis. The living bacteria attached on material surfaces were counted after they are recovered from these surfaces and grown in a separate viability assay. The recovering of bacteria was performed using a sonication method.

PUD synthesis was performed in the presence of DBTL as catalyst to prevent hydrolysis reactions of the isocyanate groups likely to proceed in case of low polyaddition kinetics. This stannic derivate is known for its biocide property. ${ }^{28,29}$ In this work, the DBTL amount was reduced as maximum as possible to neglect its effect.

Kinetics of bacteria adhesion and viability on PU surfaces were determined versus different DBTL concentrations. The curves presented on Figure 7 revealed a rapid adhesion of the bacteria on surfaces. The amount of sessile bacteria reached a steady state after $1 \mathrm{~h}$ for $P$. aeruginosa and $2 \mathrm{~h}$ for $E$. faecalis. Moreover, the number of adherent living bacteria on PU surfaces falled after $3 \mathrm{~h}$ of contact with the PU synthesized with $50 \mu \mathrm{l}$ of DBTL, while this one was constant for synthesized with $20 \mu \mathrm{l}$ of DBTL, showing that this material was not bactericidal. The nanocomposites were then synthesized by using $20 \mu \mathrm{l}$ DBTL, that is, a concentration of $0.01 \mathrm{wt}-\%$.

The kinetics of $P$. aeruginosa and $E$. faecalis adhesion and viability onto PU and PU-PEG surfaces were also determined and are presented in Figure 7. For both bacteria, a plateau was reached after 30 min of contact, meaning a very fast adhesion of the microorganisms on the material surfaces. No significant difference was observed in the case of $P$. aeruginosa in the presence of PU and PU-PEG materials. Moreover, a lower plateau value in the case of $E$. faecalis in the presence of PU-PEG could be attributed to the anti-adhesive effect of the PEG. ${ }^{4}$ The gap is very small because the amount of PEG on the surface is probably not sufficient to give a high anti-adhesive effect, especially against $P$. aeruginosa, which is a robust bacteria with big biofilm-forming abilities.

The kinetics of $P$. aeruginosa and E. faecalis adhesion and viability onto composite surfaces were investigated as a function of $\mathrm{Ag}$
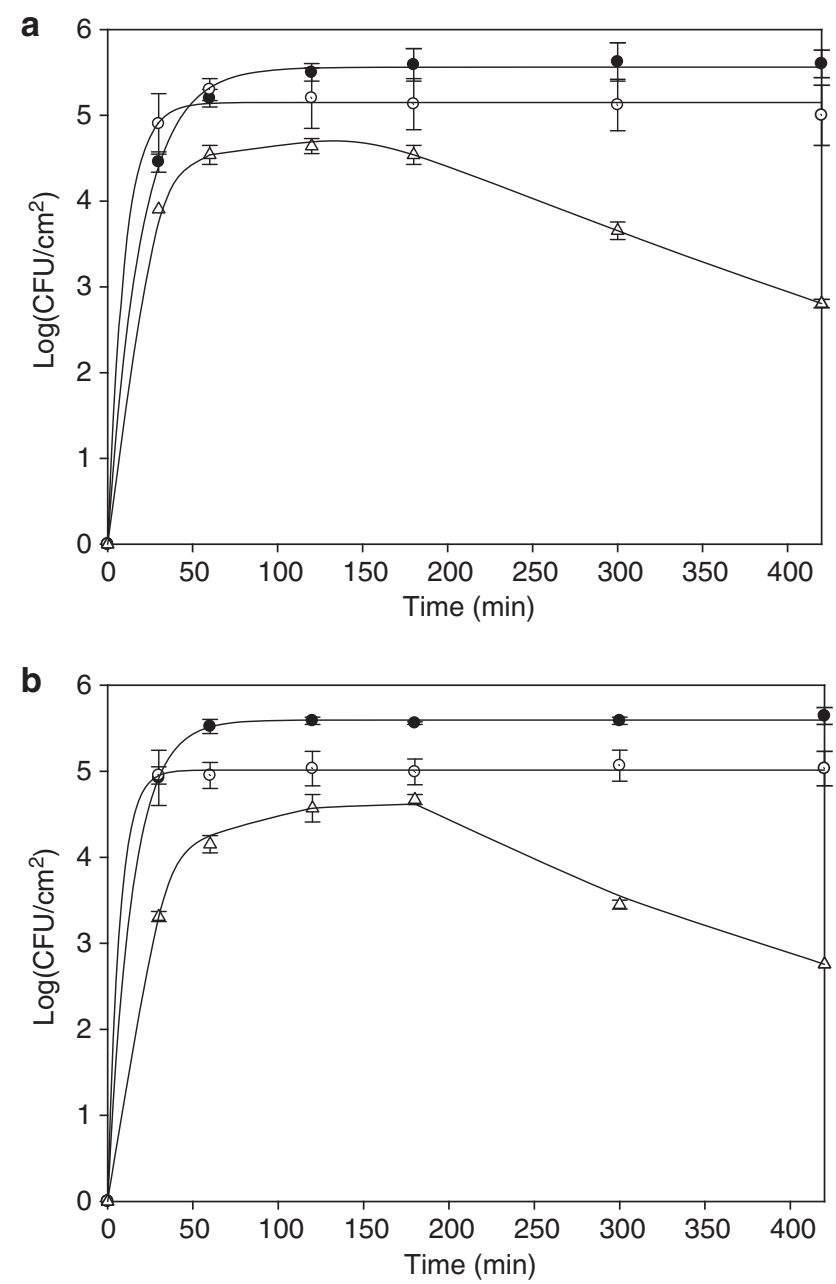

Figure 7 Kinetics of living (a) $P$. aeruginosa and (b) $E$. faecalis adhesion on PU with (•): $20 \mu \mathrm{l} \mathrm{DBTL}$ and $(\Delta): 50 \mu \mathrm{l}$ DBTL and on PU-PEG (o) with $20 \mu \mathrm{l}$ DBTL $(N D=5)$.

nanoparticle concentrations in the polymer matrix. The results presented in Figure 8 were obtained after $8 \mathrm{~h}$ of contact between bacteria and materials. For both the bacteria used, a decrease in the survived bacteria in the presence of Ag species was revealed with more important antibacterial activity for PU containing 35 p.p.m. of Ag. As reported by Hung et al., ${ }^{30}$ the surface morphology exerts a major effect on the antimicrobial adhesion of the PU-Ag nanocomposites. In particular, they demonstrated that the smaller the characteristic size of the hard segments for which the hydrophilic Ag has better affinity, the better the antibacterial activity. It is noteworthy that a similar effect was observed with a PU containing 35 p.p.m. silver ions, which confirms a real activity of silver nanoparticles.

The antibacterial property of PU-Ag nanocomposites was confirmed by live and dead tests against $P$. aeruginosa and E. faecalis. Figure 9 shows an example of images obtained against E. faecalis. Whereas all bacteria grew well on pure PU surfaces (green spots), all PU-Ag surfaces were recovered by dead bacteria (red spots) after $10 \mathrm{~min}$ of contact. The same results were observed whatever the bacteria used.

\section{Characterization of the physicochemical properties of the PU-Ag nanocomposites}

Table 1 presents the thermal and mechanical properties, and the swelling and surface properties of the PU1 material loaded by 
35 p.p.m. Ag compared with the pure PU and PU-PEG. It is noteworthy that the PEG blocks inside the PU chains did not significantly influence the overall physicochemical properties of the PU material. In the same way, the presence of low amount of silver

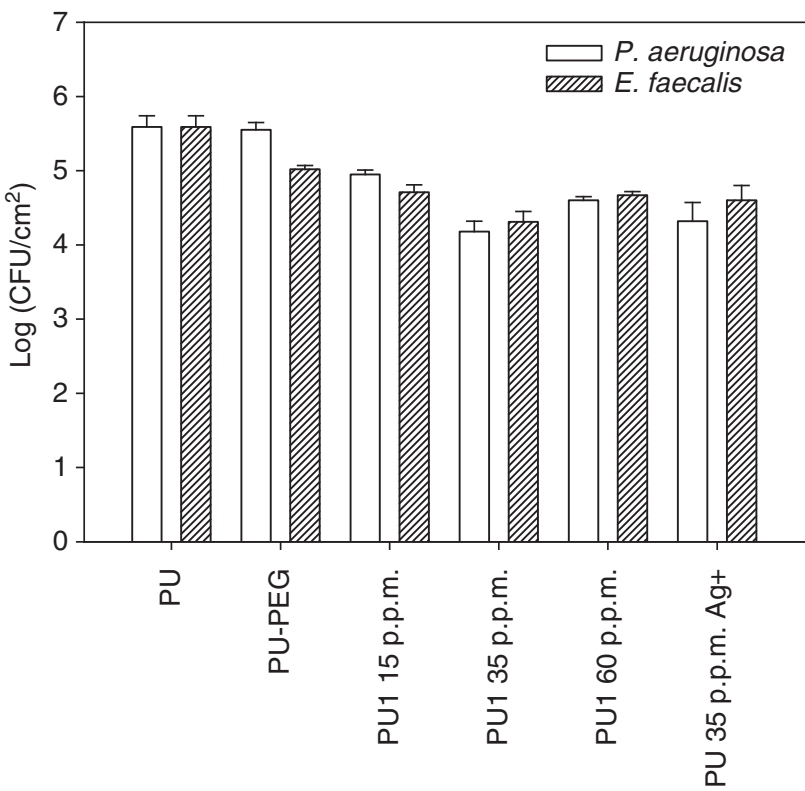

Figure 8 Evolution of the number of living bacteria versus $\mathrm{Ag}$ nanoparticles concentration inside the PU1 nanocomposites $(N D=5)$ (contact time $=8 \mathrm{~h}$ ). did not significantly affect the thermal and mechanical properties of the PU-PEG material.

\section{CONCLUSION}

By means of an easy microwave process, silver nanoparticles with well-defined size and shape were prepared by using PEG as both reducing and stabilizing agent. No additive, such as solvent, surfactant, or other reducing agent, was needed in the procedure. The size and shape of the silver nanoparticles were sensitive to the reaction temperature, the precursor $\left(\mathrm{AgNO}_{3}\right)$ concentration and the PEG molecular weight. The antibacterial activity of the obtained silver nanoparticles was assessed and MIC values of $35 \mu \mathrm{g} \mathrm{ml}^{-1}$ were determined against both a Gram-negative ( $P$. aeruginosa) and Gram-positive (E. faecalis) bacteria.

The presence of two hydroxyl groups at the chain-ends of the PEG, which constitutes the matrix of the $\mathrm{Ag}$ nanoparticles suspension, allowed its good incorporation into PU material. Indeed, the PEG incorporation on the PU backbone allowed a good distribution of the metal particles inside the final nanocomposite without aggregation. No significant variation of the intrinsic physicochemical properties of PU material was observed owing to low amount of PEG and Ag nanoparticles within the PU. On the other hand, the presence of $\mathrm{Ag}$ nanoparticles gave to the PU surfaces an antibacterial activity against P. aeruginosa and E. faecalis. The optimal activity was observed for a 35 p.p.m. Ag concentration.

\section{ACKNOWLEDGEMENTS}

We gratefully acknowledge financial support from Région Haute-Normandie (France).
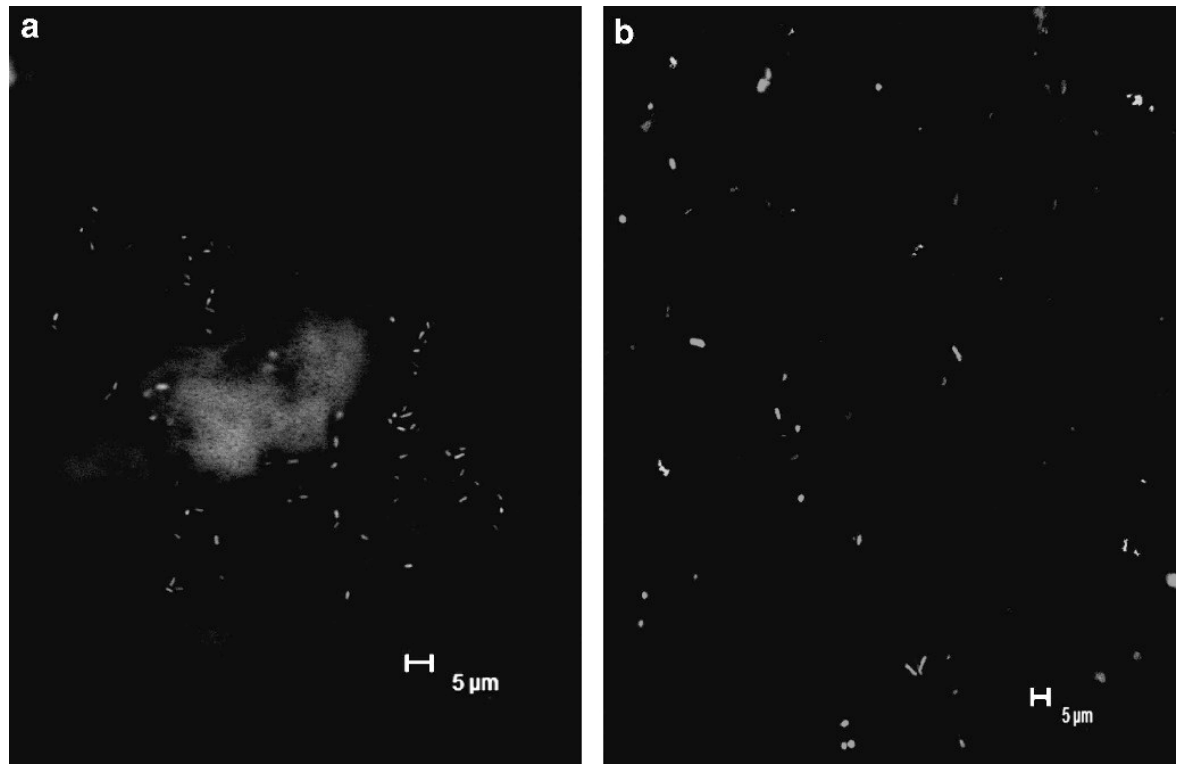

Figure 9 Confocal microscopy images of (a) PU-PEG and (b) PU1 nanocomposite (35 p.p.m. Ag) surfaces after live and dead test against E. faecalis. A ful color version of this figure is available at The Journal of Antibiotics journal online.

Table 1 A comparison of physicochemical properties of pure PU, PU-PEG and PU1 materials

\begin{tabular}{|c|c|c|c|c|c|c|c|c|c|}
\hline & $\left.\mathrm{T}_{d^{1}}{ }^{\circ} \mathrm{C}\right)$ & $\mathrm{T}_{d}^{2}\left({ }^{\circ} \mathrm{C}\right)$ & $\operatorname{Tg}\left({ }^{\circ} \mathrm{C}\right)$ & $E(M P a)$ & $\varepsilon_{f}(\%)$ & $\mathrm{Q}(\%)$ & $\gamma_{s}^{p}\left(m N m^{-1}\right)$ & $\gamma_{s}^{d}\left(m N m^{-1}\right)$ & $\mathrm{P}(\%)$ \\
\hline Pure PU & 327 & 423 & -26 & $7.4 \pm 1.0$ & $760 \pm 30$ & $2.0 \pm 0.5$ & 8.2 & 16.9 & $32 \pm 2$ \\
\hline PU-PEG & 331 & 412 & -30 & $5.0 \pm 0.1$ & $830 \pm 25$ & $5 \pm 1$ & 11 & 18.0 & $37 \pm 3$ \\
\hline PU1 (35 p.p.m. Ag(PEG)) & 320 & 400 & -31 & $5.4 \pm 0.3$ & $930 \pm 20$ & $5 \pm 1$ & 12.9 & 18.8 & $39 \pm 3$ \\
\hline
\end{tabular}

Abbreviations: $E$, Young's modulus; $P$, surface polarity; PEG, poly(ethylene glycol); PU, polyurethane; $\mathrm{Q}$, swelling in water; $T_{\mathrm{d}}{ }^{1}$, degradation temperature of soft segments; $T_{\mathrm{d}}{ }^{2}$, degradation temperature of hard segments; $\mathrm{Tg}$, glass transition temperature of soft segments (tetraethoxy groups); $\varepsilon_{\mathrm{f}}$, failure strain; $\gamma_{\mathrm{s}}^{\mathrm{d}}$. dispersive component; $\gamma_{\mathrm{s}}^{\mathrm{p}}$. polar component. 
1 Lamba, N., Woodhouse, K. \& Cooper, S. Polyurethanes in biomedical applications (CRC press, Boca Raton, FL, 1998).

2 Hsu, S., Tseng, H. \& Wu, M. Comparative in vitro evaluation of two different preparations of small diameter polyurethane vascular grafts. Artif. Organs 24, 119-128 (2000).

3 Kim, B. \& Lee, J. Waterborne polyurethanes and theirproperties. J. Polym. Sci. A Polym. Chem. 34, 1095-1104 (1996).

4 Humphries, M., Jaworzyn, J. F., Cantwell, J. B. \& Eakin, A. The use of non-ionic ethoxylated and propoxylated surfactants to prevent the adhesion of bacteria to solid surfaces. FEMS Microbiol. Lett. 42, 91-101 (1987).

5 Huajiang, Z., Dingcai, W. \& Ruowen, F. Synthesis of antibacterial polymers from 2-dimethylamino ethyl methacrylate quaternized by dimethyl sulphate. Polym. J 42, 766-771 (2010).

6 Zhang, W., Zhang, Y. H., Ji, J. H., Zhao, J., Yan, Q. \& Chu, P. K. Antimicrobial properties of copper plasma-modified polyethylene. Polymer 47, 7441-7445 (2006).

7 An, J., Luo, Q., Yuan, X., Wang, D. \& Li, X. Preparation and characterization of silverchitosan nanocomposite particles with antimicrobial activity. J. Appl. Polym. Sci. 120, 3180-3189 (2011)

8 Takashi, K., Yoko, T., Gang, W., Kumi, S., Takeshi, Y. \& Norio, T. Preparation of antibacterial polymer-grafted silica nanoparticle and surface properties of composites filled with the silica (2) antibacterial polymergrafted silica nanoparticle. Polym. J. 41, 744-751 (2009).

9 Panáček, A., Kvítek, L., Prucek, R., Kolář, M., Večeřová, R., Pizúrová, N., Sharma, V. K., Tat'jana, N. \& Zbořil, Z. Silver colloid nanoparticles: synthesis, characterization, and their antibacterial activity. J. Phys. Chem. B 110, 16248-16253 (2006).

$10 \mathrm{Holt}, \mathrm{K}$. B. \& Bard, A. J. Interaction of silver (I) ions with the respiratory chain of Escherichia coli: an electrochemical and scanning electrochemical microscopy study of the antimicrobial mechanism of micromolar $\mathrm{Ag}^{+}$. Biochemistry 44, 13214-13223 (2005).

11 Shrivastava, S., Bera, T., Roy, A., Singh, G., Ramachandrarao, P. \& Dash, D. Characterization of enhanced antibacterial effects of novel silver nanoparticles. Nanotechnology 18, 225103/1-225103/9 (2007).

12 Zhang, L., Yu, J. C., Yip, H. Y., Li, Q., Kwong, K. W., Xu, A. \& Wong, P. K. Ambient light reduction strategy to synthesize silver nanoparticles and silver-coated $\mathrm{TiO}_{2}$ with enhanced photocatalytic and bactericidal activities. Langmuir 19, 10372-10380 (2003).

$13 \mathrm{Pal}, \mathrm{S}$., Tak, Y. K. \& Song, J. M. Does the antibacterial activity of silver nanoparticles depend on the shape of the nanoparticle? a study of the gram-negative bacterium Escherichia coli. Appl. Environ. Microbiol. 73, 1712-1720 (2007).

14 Luo, C., Zhang, Y., Zeng, X., Zeng, Y. \& Wang, Y. The role of poly(ethylene glycol) in the formation of silver nanoparticles. J. Coll. Inter. Sci. 288, 444-448 (2005).
$15 \mathrm{Li}$, P., Li, J., Wu, C., Wu, Q. \& Li, J. Synergistic antibacterial effects of lactum antibiotic combined with silver nanoparticles. Nanotechnology 16, 1912-1917 (2005).

16 Carotenuto, G. \& Nicolais, L. Size-controlled synthesis of thiol-derivatized gold clusters. J. Mater. Chem. 13, 1038-1041 (2003).

17 Hutter, E. \& Fendler, J. H. Exploitation of localized surface plasmon resonance. Adv. Mater. 16, 1685-1706 (2004).

18 Murugadoss, A. \& Chattopadhyay, A. A. 'Green' chitosan-silver nanoparticle composite as a heterogeneous as well as micro-heterogeneous catalyst. Nanotechnology 19, 015603/1-015603/9 (2008).

19 Pal, A., Shah, S. \& Devi, S. Preparation of silver-gold alloy nanoparticles at higher concentration using sodium dodecyl sulfate. Aust. J. Chem. 61, 66-71 (2008).

20 Raveendran, P., Fu, J. \& Wallen, S. L. Complete 'green' synthesis and stabilization of metal nanoparticles. J. Am. Chem. Soc. 125, 13940-13941 (2003).

21 Tsuji, M., Hashimoto, M., Nishizawa, Y., Kubokawa, M. \& Tsuji, T. Microwaveassisted synthesis of metallic nanostructures in solution. Chem. Eur. J 11, 440-452 (2005).

22 Zhu, Y. J. \& Hu, X. L. Microwave-assisted polythiol reduction method: a new solidliquid route to fast preparation of silver nanowires. Mater. Lett 58, 1517-1519 (2004).

23 Jana, N. R., Sau, T. K. \& Pal, T. Growing small silver particle as redox catalyst. J. Phys. Chem. B 103, 115-121 (1999).

24 Manna, A., Imae, T., Aoi, K., Okada, M. \& Yogo, T. Synthesis of dendrimer-passivated noble metal nanoparticles in a polar medium: Comparison of size between silver and gold particles. Chem. Mater. 13, 1674-1681 (2001).

25 Kheybari, S., Samadi, N., Hosseini, S. V., Fazeli, A. \& Fazeli, M. R. Synthesis and antimicrobial effects of silver nanoparticles produced by chemical reduction method. Daru 18, 168-172 (2010).

26 Couvercelle, J. P., Bailleul, V. \& Bunel, C. Synthesis, dispersion and properties of hydroxy polybutadiene-based anionic polyurethane-urea. Macromol. Symp. 151, 347-352 (2000).

27 Couvercelle, J. P., Bailleul, V., Poussard, L. \& Bunel, C. Preparation of hydrodispersible polyurethane-urea anionomers based on hydroxytelechelic polybutadiene. Synthesisdispersion - material properties. Entropie 37, 48-55 (2001).

28 Kebir, N., Campistron, I., Laguerre, A., Pilard, J. F., Bunel, C. \& Jouenne, T. Use of telechelic. Biomaterials 28, 4200-4208 (2007).

29 Champ, M. A. A review of organotin regulatory strategies, pending actions, related costs and benefits. Sci. Total Environ. 258, 21-71 (2000).

30 Hung, H. S. \& Hsu, S. H. Biological performances of poly(ether)urethane-silver nanocomposites. Nanotechnology 18, 475101-475110 (2007). 